\title{
Association of professional identity, job satisfaction and burnout with turnover intention among general practitioners in China: evidence from a national survey
}

Tao Zhang ${ }^{1,2+}$, Jing Feng ${ }^{3+}$, Heng Jiang ${ }^{4,5}$, Xin Shen ${ }^{3}$, Bo Pu ${ }^{6}$ and Yong Gan ${ }^{3 *}$

\begin{abstract}
Background: The complex interrelationships between professional identity, job satisfaction, burnout, and turnover intention among general practitioners (GPs) are insufficiently understood in China. This study aimed to investigate the interrelationships between professional identity, job satisfaction, burnout, and turnover intention in China, and to examine whether job satisfaction and burnout played mediating roles between professional identity and turnover intention.

Methods: A cross-sectional survey was conducted between October, 2017 and February, 2018 in China. The participants were selected using a multistage stratified random sampling method. Data were collected with a selfadministered questionnaire from 3236 GPs (response rate, 99.8\%) working in community health institutions in China. Professional identity was measured by the 13 items scale, and job satisfaction scale with an 11-item designed by Shi et al. was employed. Burnout was measured using a 22-item Maslach Burnout Inventory-Human Services Survey, and turnover intention was measured with a 6 items scale. Descriptive statistics were calculated and groups' differences were estimated Student's t-test and analyses of variance. Pearson's correlation analysis was used to assess the degree of correlation among different dimensions of professional identity, job satisfaction, burnout, and turnover intention. Structural equation modeling analysis was applied to examine the interrelationships among these study variables based on the hypothesized model.
\end{abstract}

Results: The proposed model achieved a good model fit. Job satisfaction had a direct negative effect on turnover intention ( $\beta=-0.38, P<0.001)$, burnout had a direct positive effect on turnover intention $(\beta=0.37, P<0.001)$, and professional identity had an indirect negative effect on turnover intention through the mediating effect of job satisfaction and burnout.

(Continued on next page)

\footnotetext{
* Correspondence: scswi2008@163.com

${ }^{\dagger}$ Tao Zhang and Jing Feng contributed equally to this work.

${ }^{3}$ Department of Social Medicine and Health Management, School of Public

Health, Tongji Medical College, Huazhong University of Science and

Technology, No. 13 Hangkong Road, Wuhan 430030, Hubei, China

Full list of author information is available at the end of the article
}

C C The Author(s). 2021 Open Access This article is licensed under a Creative Commons Attribution 4.0 International License, which permits use, sharing, adaptation, distribution and reproduction in any medium or format, as long as you give appropriate credit to the original author(s) and the source, provide a link to the Creative Commons licence, and indicate if changes were made. The images or other third party material in this article are included in the article's Creative Commons licence, unless indicated otherwise in a credit line to the material. If material is not included in the article's Creative Commons licence and your intended use is not permitted by statutory regulation or exceeds the permitted use, you will need to obtain permission directly from the copyright holder. To view a copy of this licence, visit http://creativecommons.org/licenses/by/4.0/. The Creative Commons Public Domain Dedication waiver (http://creativecommons.org/publicdomain/zero/1.0/) applies to the data made available in this article, unless otherwise stated in a credit line to the data. 
(Continued from previous page)

Conclusions: Our study elucidated the pathways linking professional identity, job satisfaction, and burnout to turnover intention of GPs. This revealed that turnover intention was significantly affected by job satisfaction and burnout, and the effects of professional identity on turnover intention can be mediated by job satisfaction and burnout.

Keywords: Primary care, General practitioner, Turnover intention, Job satisfaction, Professional identity, Burnout

\section{Background}

Providing adequate and high-quality primary healthcare has been considered as a priority in the health care system with rapid population aging around the world. General practitioners (GPs), gatekeepers for residents' health, are the main providers of primary healthcare services and supposed to provide a wide range of economical, convenient and highly comprehensive health services $[1,2]$. These basic health services can sustain the equality and efficiency of overall health care services, as well as control the increase in medical costs [3]. Therefore, many developed countries have established a relatively comprehensive GPs system and paid more attention to GPs' career development and training.

Since China's new round of health system reform in 2009, improving the capability of primary healthcare institutions has been positioned as the core task of the reform [4]. Thereafter, Chinese government launched a new plan for the GP system with a goal of providing five GPs for every 10,000 people by 2030 , which aimed to shift patients away from overcrowded hospitals and take the strain off the current healthcare system [5]. In order to achieve such goal, many efforts have been taken to train and recruit GPs. For example, the new " $5+3$ " model of medical education was introduced in 2015. Medical students who have completed a 5 -year bachelor's degree can choose to finish a 3-year standardized clinical training if they intend to become GPs [6, 7]. Not surprisingly, these efforts have created an encouraging progress. For instance, the number of GPs per 10,000 population increased from 0.8 in 2012 to 2.2 in 2018 [8]. However, the shortage of health workers and high turnover rate among on-post GPs still are the urgent issue in primary healthcare sectors in China [9].

Previous studies showed that GPs in primary health institutions [community health centres (CHCs) and township health centres (THCs)] had a high-level turnover rate, especially in poor regions [10, 11]. Although Chinese government has attempted to improve working conditions and levels of wage for primary health workers, GPs' turnover intention still remained at a high level [12]. Thus, understanding factors associated with GPs' turnover intention become particularly important in current Chinese context.
Several studies have investigated potential factors correlated to GPs' turnover intention, such as low income, high work stress, high professional title and limited professional development opportunities $[1,11$, 13-18]. However, these studies mainly focused on demographics factors and job characteristics, and many other potential factors (such as professional identity, job satisfaction and burnout) were neglected. The heuristic model of the employee withdrawal decision process proposed by Mobley indicated a significant correlation between job satisfaction and turnover intention [19]. Simultaneously, studies of the attitude theory in psychology revealed that employees' perception and evaluation on their works (job satisfaction) have an negative association with their emotional response (burnout) [20, 21]. Additionally, professional identity is other important factor which is referred to one's perception on social significance and value of works he/she engages, and has been demonstrated an evident association with job satisfaction, burnout and turnover intention among nurses and specialists [22, 23]. Therefore, job satisfaction, burnout, and professional identity should be considered as important factors for turnover intention among GPs. Also, it is assumed that associations between these variables and turnover intention are not only direct, but some indirect mediating effects could exist. For example, the relationship between job satisfaction and turnover intention may be mediated by burnout. However, no studies provide a clear insight on these complex interrelationships among Chinese GPs working in the community health institutions (CHIs) based on a national representative sample.

Based on above review, this study aimed to fill the research gap by analysing the interrelationships between professional identity, job satisfaction, burnout, and turnover intention among Chinese GPs using a national survey data. As illustrated in Fig. 1, we proposed the following hypotheses: (1) professional identity and job satisfaction have a negative association with GP's turnover intention, while the correlation between burnout and turnover intention is positive; (2) the relationship between professional identity and turnover intention would be mediated by both job satisfaction and burnout; (3) burnout also creates a 


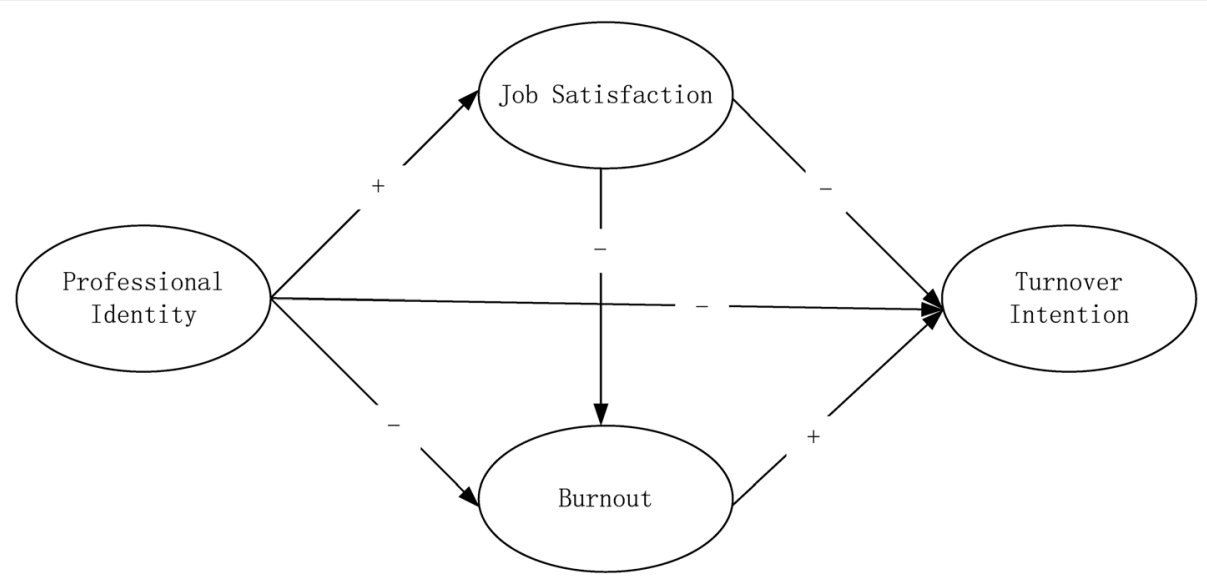

Fig. 1 Hypothetical model of relationships between professional identity, job satisfaction, burnout, and turnover intention among Chinese urban GPs

mediation effect on the relationship between job satisfaction and turnover intention.

\section{Methods}

\section{Study population and sampling}

A cross-sectional survey was conducted in China from 10th October 2017 to 28th February 2018. In this survey, a multistage sampling strategy was applied for data collection. Firstly, we chose 4 provinces and municipalities from each of three different levels of economic development and geographical regions, namely: Shanghai, Beijing, Guangdong, and Zhejiang in the eastern region; Hubei, Anhui, Heilongjiang, and Henan in the central region; Sichuan, Chongqing, Guizhou, and Yunnan in western China region. Secondly, $30 \mathrm{CHIs}$ including $\mathrm{CHCs}$ and community health stations (CHSs) were randomly selected according to agency code from each province, which resulted in a total of 360 participating CHIs. Thirdly, according to the number of GPs and scales of CHIs, $40 \%$ of the on-post GPs with at least one-year work experience from each sampled CHIs were randomly invited to participate in the survey. In order to capture a representative sample, we approached potential participants who were on duty during the survey period. In total, 3244 urban GPs were invited to complete a self-administered questionnaire (Additional file 1) [24]. Of those invited participants, 3236 $(99.75 \%)$ returned valid questionnaires for data analyses. The excluded questionnaires $(n=8)$ contained incomplete data on the four scales measurement. The remaining sample was large enough to establish our model containing 15 variables [25]. A power analysis for the not close model fit $(\alpha=0.05$; statistical power $=0.95$; null root mean square error of approximation $($ RMSEA $)=0.05$; and alternative $\operatorname{RMSEA}=0.08$
[26]; $\mathrm{df}=39$ ) showed the minimum sample size of 402 [27]. Thus, the sample size was sufficient in our study.

The study protocol was approved by the Ethics Committee of the Tongji Medical College Institutional Review Board, Huazhong University of Science and Technology, Wuhan, China (No. [2018] IEC (S186)). All the participating doctors gave their informed consent before completing the questionnaire.

\section{Instrument and measurement \\ Demographic characteristics}

Demographic information captured in the survey included gender, age, marital status, education, income level, professional title, employment status, work tenure and working hours (Table 1). Self-rated income level was measured by an item on "what was the level of your income in your local city or region?" (below the moderate, at the moderate level, or higher than the moderate). Work hours referred to average working hours per day for GPs.

\section{Turnover intention}

Turnover intention scale (TIS-6), developed by Michaels et al. and revised by $\mathrm{Li}$ et al. for the Chinese population, was used to measure GPs' intention to resign in this study $[28,29]$. This scale included six items, for example "Have you considered resigning from your current job?". Items 1 and 6 measured the intent to resign from the current job (TIS-I); items 2 and 3 represented the motivation to search for other jobs (TIS-II); and items 4 and 5 indicated the probability of obtaining a new job (TISIII). Each item was rated with a four-point Likert scale, ranging from 1 (never) to 4 (always). Consequently, the total score of six items ranged from 6 to 24 and a higher score indicated stronger turnover intention. The scores 
Table 1 Characteristics of respondents and differences in professional identity, job satisfaction, burnout and turnover intention scores among different characteristics groups (mean \pm SD)

\begin{tabular}{|c|c|c|c|c|c|}
\hline Characteristics of respondents & $N(\%)$ & Professional identity & Job satisfaction & Burnout & Turnover intention \\
\hline \multicolumn{6}{|l|}{ Gender } \\
\hline Male & $1170(36.2)$ & $51.46 \pm 6.91$ & $36.47 \pm 7.75$ & $61.10 \pm 22.45$ & $15.42 \pm 4.49$ \\
\hline Female & $2066(63.8)$ & $51.09 \pm 7.13$ & $37.67 \pm 6.85$ & $59.56 \pm 20.60$ & $14.86 \pm 4.22$ \\
\hline t & & 1.43 & -4.56 & 1.98 & 3.53 \\
\hline$p$ & & 0.15 & $<0.001$ & 0.04 & $<0.001$ \\
\hline \multicolumn{6}{|l|}{ Age (years) } \\
\hline$\leq 30$ & $689(21.3)$ & $50.51 \pm 7.05$ & $37.57 \pm 7.58$ & $63.64 \pm 20.79$ & $15.33 \pm 4.31$ \\
\hline $31-40$ & $1469(45.4)$ & $51.07 \pm 7.12$ & $37.01 \pm 7.17$ & $61.62 \pm 20.96$ & $15.57 \pm 4.01$ \\
\hline $41-50$ & $914(28.2)$ & $51.69 \pm 7.11$ & $37.01 \pm 7.07$ & $56.86 \pm 21.44$ & $14.45 \pm 4.52$ \\
\hline$\geq 51$ & $164(5.1)$ & $52.89 \pm 5.58$ & $39.17 \pm 6.40$ & $49.96 \pm 20.29$ & $12.76 \pm 4.90$ \\
\hline F & & 6.97 & 5.19 & 29.05 & 29.94 \\
\hline$p$ & & $<0.001$ & 0.001 & $<0.001$ & $<0.001$ \\
\hline \multicolumn{6}{|l|}{ Marital status } \\
\hline Non-married & $382(11.8)$ & $50.07 \pm 7.28$ & $37.33 \pm 7.79$ & $64.46 \pm 21.68$ & $15.43 \pm 4.31$ \\
\hline Married & $2771(85.6)$ & $51.35 \pm 7.00$ & $37.21 \pm 7.12$ & $59.57 \pm 21.15$ & $15.04 \pm 4.31$ \\
\hline Others & $83(2.6)$ & $52.22 \pm 7.37$ & $37.85 \pm 7.49$ & $58.25 \pm 22.36$ & $14.04 \pm 4.71$ \\
\hline F & & 6.43 & 0.35 & 9.19 & 3.71 \\
\hline$p$ & & 0.001 & 0.70 & $<0.001$ & 0.25 \\
\hline \multicolumn{6}{|l|}{ Education level } \\
\hline Associate's degree or below & $918(28.4)$ & $51.15 \pm 7.04$ & $38.05 \pm 7.39$ & $57.71 \pm 21.78$ & $14.26 \pm 4.65$ \\
\hline Bachelor's degree & $2139(66.1)$ & $51.25 \pm 6.98$ & $36.92 \pm 7.07$ & $61.13 \pm 21.06$ & $15.32 \pm 4.15$ \\
\hline Master's degree or above & $179(5.5)$ & $51.22 \pm 8.00$ & $36.91 \pm 7.61$ & $60.32 \pm 20.71$ & $16.07 \pm 4.02$ \\
\hline F & & 0.07 & 8.06 & 8.32 & 24.73 \\
\hline$p$ & & 0.93 & $<0.001$ & $<0.001$ & $<0.001$ \\
\hline \multicolumn{6}{|l|}{ Income level } \\
\hline Low & $2281(70.5)$ & $50.56 \pm 7.22$ & $36.13 \pm 7.10$ & $61.81 \pm 21.49$ & $15.54 \pm 4.21$ \\
\hline Middle & $864(26.7)$ & $52.42 \pm 6.28$ & $39.86 \pm 6.64$ & $55.89 \pm 20.42$ & $13.99 \pm 4.30$ \\
\hline High & $91(2.8)$ & $54.06 \pm 7.74$ & $40.09 \pm 7.95$ & $57.73 \pm 18.98$ & $13.34 \pm 5.05$ \\
\hline F & & 27.69 & 96.48 & 25.17 & 48.59 \\
\hline$p$ & & $<0.001$ & $<0.001$ & $<0.001$ & $<0.001$ \\
\hline \multicolumn{6}{|l|}{ Professional title } \\
\hline Junior & $1419(43.9)$ & $50.87 \pm 7.01$ & $37.65 \pm 7.56$ & $60.88 \pm 21.49$ & $15.08 \pm 4.41$ \\
\hline Middle & $1412(43.6)$ & $51.30 \pm 7.11$ & $36.68 \pm 6.92$ & $60.36 \pm 21.22$ & $15.17 \pm 4.23$ \\
\hline Senior & $405(12.5)$ & $52.18 \pm 6.96$ & $37.71 \pm 6.82$ & $56.59 \pm 20.60$ & $14.61 \pm 4.36$ \\
\hline$F$ & & 5.54 & 7.18 & 6.57 & 2.60 \\
\hline$p$ & & 0.01 & 0.001 & 0.001 & 0.07 \\
\hline \multicolumn{6}{|l|}{ Employment status } \\
\hline Permanent employee & $2185(67.5)$ & $51.18 \pm 7.13$ & $37.03 \pm 7.07$ & $60.67 \pm 21.01$ & $14.86 \pm 4.21$ \\
\hline Contract employee & $789(24.4)$ & $51.31 \pm 6.88$ & $37.84 \pm 7.21$ & $58.69 \pm 21.78$ & $15.44 \pm 4.42$ \\
\hline Others & $262(8.1)$ & $51.27 \pm 6.99$ & $37.20 \pm 8.23$ & $59.78 \pm 22.09$ & $15.63 \pm 4.82$ \\
\hline$t$ & & 0.10 & 3.63 & 2.54 & 7.65 \\
\hline$p$ & & 0.90 & 0.26 & 0.79 & $<0.001$ \\
\hline
\end{tabular}


Table 1 Characteristics of respondents and differences in professional identity, job satisfaction, burnout and turnover intention scores among different characteristics groups (mean \pm SD) (Continued)

\begin{tabular}{|c|c|c|c|c|c|}
\hline Characteristics of respondents & $N(\%)$ & Professional identity & Job satisfaction & Burnout & Turnover intention \\
\hline \multicolumn{6}{|l|}{ Work tenure (years) } \\
\hline $1-3$ & $993(30.7)$ & $50.45 \pm 7.26$ & $37.14 \pm 7.53$ & $61.48 \pm 21.73$ & $15.46 \pm 4.35$ \\
\hline $4-10$ & 1607 (49.7) & $51.63 \pm 6.78$ & $37.38 \pm 7.20$ & $60.07 \pm 20.66$ & $15.08 \pm 4.20$ \\
\hline$\geq 11$ & $636(19.7)$ & $51.39 \pm 7.32$ & $37.03 \pm 6.71$ & $58.12 \pm 22.06$ & $14.39 \pm 4.52$ \\
\hline F & & 8.77 & 0.66 & 4.84 & 12.05 \\
\hline$p$ & & $<0.001$ & 0.51 & 0.01 & $<0.001$ \\
\hline \multicolumn{6}{|l|}{ Working hours (hours) } \\
\hline$\leq 8$ & $2374(73.4)$ & $51.16 \pm 6.78$ & $37.76 \pm 7.08$ & $58.80 \pm 20.70$ & $14.79 \pm 4.32$ \\
\hline$\geq 9$ & $862(26.6)$ & $51.40 \pm 7.55$ & $35.79 \pm 7.37$ & $63.73 \pm 22.49$ & $15.81 \pm 4.26$ \\
\hline t & & 0.78 & 47.84 & 34.18 & 35.39 \\
\hline$p$ & & 0.37 & $<0.001$ & $<0.001$ & $<0.001$ \\
\hline
\end{tabular}

of $0-6,7-12,13-18$, and 19-24 were assigned for the low, moderate, moderate to high and high degree of turnover intention, respectively [29]. In this study, the Cronbach's alpha coefficient for the scale was 0.89 , indicating a good internal consistency.

\section{Burnout}

Burnout was measured using the Chinese version of anonymous Maslach Burnout Inventory-Human Services Survey (MBI-HSS) questionnaire including three subscales: emotional exhaustion (EE, 9 items), depersonalization (DP, 5 items), and personal achievement (PA, 8 items) [30]. EE describes the feelings of being emotionally overextended and exhausted by one's work; DP measures an unfeeling and impersonal response towards recipients of one's care or service and PA indicates feelings of competence and successful achievement in one's work with people. Each item in three subscales is scored according to how often the statement is experienced, from 'never' (0) to 'every day' (6). Higher scores on the EE and DP subscales indicate the higher degrees of burnout, while PA is inversely correlated with burnout. The reversed scores of the PA were used to estimate the burnout. The summary scores for burnout range from 0 to 132, with high scores representing high degrees of burnout. The Cronbach's alphas for the MBI-HSS, EE, DP, and PA were 0.89, 0.94, 0.90 and 0.88 , respectively.

\section{Job satisfaction}

Job satisfaction scale developed by Shi et al. was used to assess GPs' satisfaction. A total of 11 items in this scale were rated using a five-point ordinal scale ranging from 1 (very dissatisfied) to 5 (very satisfied). These items can be divided into 3 dimensions: satisfaction on relationship (4 items), satisfaction on personal development (3 items) and satisfaction on basic demand (4 items) [31]. The total scores of job satisfaction ranged from 11 to 55 , with higher scores indicating a higher level of satisfaction. The Cronbach's alpha for this scale, material satisfaction, relationship satisfaction, and growth satisfaction was $0.91,0.82,0.77$, and 0.86 , respectively.

\section{Professional identity}

According to Zhao et al. and Wu's study [32, 33], the Chinese version of professional identity scale in this study was measured using 13 items. Each statement was asked to response from very disagree (1) to very agree (5). This scale can be divided into 2 dimensions: professional value ( 9 items) and professional efficacy (4 items). Professional value tended to measure GPs' perception on social value and meaning of their works, for example, "The work I do is important to the health of the patient". Professional efficacy focused on GPs' perception on personal accomplishment and honour in regard to their works, for example "Others praise my profession, just like praise to me". The item scores were summed to provide a composite score of professional identity (range: 13 to 65) and a high score represented higher professional identity. In the present study, the Cronbach's alpha for this scale was 0.91 .

\section{Data collection and quality control}

The questionnaire was designed based on a literature review, group discussions, and mock interviews. Furthermore, to improve the quality of the questionnaire, a pilot study was conducted in Wuhan's CHIs. A web link of the online questionnaire, created by the Questionnaire Star software, was then disseminated to GPs through WeChat (the biggest communication platform in China with over one billion users, similar to WhatsApp in western countries). The data were entered into the webbased database by specialized investigators to ensure accuracy. 


\section{Statistical analysis}

Demographic characteristics of respondents were described using number and percentages. Student's $t$-test and analyses of variance were conducted to test the statistical differences in professional identity, job satisfaction, burnout and turnover intention scores across different subgroups. Pearson's correlation was used to assess the degree of correlation among different dimensions of these attributes. The above analyses were conducted using IBM SPSS Statistics 22.0 and the significance level was set at $P<0.05$.

Structural equation modeling (SEM) performing on the AMOS 21.0 was conducted to further verify the hypothetical relationship among the four concepts of professional identity, job satisfaction, burnout, and turnover intention. This technique allowed us to decompose total effects of variables into direct and indirect effects [34]. As such, the results can provide a deep understanding for mechanisms and pathways of these variables. We also used a bias-corrected bootstrap 95\% confidence interval (CI) to assess significance of total, direct and indirect effects [35].

Considering that sample characteristics, such as age, gender, education level, employment status, income level, and work hours, were associated with professional identity, job satisfaction, burnout and turnover intention, we adjusted these variables using classical multiple regression models (i.e., residual scores were obtained through regression) to control the influence of socio-demographic factors [36]. As a result, the regressed data was used in the SEM analysis. To assess the overall model fit, the four tests were used: RMSEA, goodness-of-fit index (GFI), comparative fit index (CFI), and Tucker-Lewis index (TLI). If GFI, CFI and TLI values above 0.90 and RMSEA values below 0.08 , it indicates the model fit is acceptable [37].

\section{Results}

\section{Characteristics of respondents}

Of 3, 236 respondents, more than half of GPs were female. GPs aged from 31 to 40 accounted for $45.4 \%$ of the sample. Most respondents were married (85.6\%) and had a bachelor degree (66.1\%). Over $70 \%$ of GPs gave a low rating on their income level, and a small percentage of GPs (12.5\%) had a senior profession title. About a quarter of respondents were employed as contracted workers and worked more than $8 \mathrm{~h}$ a day on average. Approximately half of GPs had worked for 4 to 10 years (Table 1).

\section{Differences in scores across different groups}

Overall, the GPs gave a rating score of $51.22 \pm 7.06$, $37.24 \pm 7.21, \quad 60.12 \pm 21.30, \quad$ and $15.06 \pm 4.33$ for professional identity, job satisfaction, burnout, and turnover intention, respectively.

The differences in mean scores of professional identity, job satisfaction, burnout, and turnover intention among the different subgroups were presented in Table 1. Older GPs were more likely to give a positive rating on these four attributes $(P<0.001)$. Those who had a higher level of income also reported a higher professional identity, job satisfaction as well as lower burnout and turnover intention $(P<0.001)$.

Gender difference in scores was found in the job satisfaction, burnout and turnover intention $(P<0.05)$. There was significant difference in professional identity and burnout scores by marital status $(P<0.001)$. Respondents with different educational levels and working hours reported different scores in job satisfaction, burnout and turnover intention $(P<0.001)$. Those GPs with senior professional title tended to give a positive rating on professional identity, job satisfaction and burnout $(P<0.01)$. Difference in turnover intention was found among different employment type $(P<0.001)$. Those who had longer work tenure were more likely to reported a higher level of professional identity and lower level of burnout and turnover intention $(P<0.01)$.

\section{Correlations among professional identity, job satisfaction, burnout and turnover intention}

Table 2 shows correlation coefficients between professional identity, job satisfaction, burnout and turnover intention. Overall, most of the coefficients were statistically significant at the $P<0.001$ level. Specifically, professional identity was positively associated with job satisfaction, as well as negatively associated with burnout and turnover intention. Job satisfaction had both negative associations with burnout and turnover intention. Additionally, the association between burnout and turnover intention was significantly positive.

\section{Synthesized relationship among professional identity, job satisfaction, burnout, and turnover intention: results from SEM}

Figure 2 shows the model paths with standardized coefficients and Table 3 provides total, direct, and indirect effects of model paths. The significance of all the effects were examined using a 95\% bootstrapped confidence interval estimate. The overall fit of the model was high based on the four goodnessof-fit indices: $\quad$ RMSEA $=0.008, \quad \mathrm{CFI}=0.918, \quad \mathrm{GFI}=$ $0.934, \mathrm{TLI}=0.926$.

Overall, almost all effects of model paths were significant. Specifically, job satisfaction $(\beta=-0.42,95 \% \mathrm{CI}$ : 0.47 to -0.36$)$ and burnout $(\beta=0.37,95 \% C I$ : 0.32 to 
Table 2 Correlation coefficients of professional identity, job satisfaction, burnout, and turnover intention

\begin{tabular}{|c|c|c|c|c|c|c|c|c|c|c|c|}
\hline & 1 & 2 & 3 & 4 & 5 & 6 & 7 & 8 & 9 & 10 & 11 \\
\hline \multicolumn{12}{|l|}{ Professional identity } \\
\hline 1. Professional value & 1 & & & & & & & & & & \\
\hline 2. Professional efficacy & $0.600^{* *}$ & 1 & & & & & & & & & \\
\hline \multicolumn{12}{|l|}{ Job satisfaction } \\
\hline 3. Basic demand & $0.203^{* *}$ & $0.204^{* *}$ & 1 & & & & & & & & \\
\hline 4. Relationship & $0.344^{* *}$ & $0.282^{* *}$ & $0.675^{* *}$ & 1 & & & & & & & \\
\hline 5. Personal development & $0.196^{* *}$ & $0.198^{* *}$ & $0.639^{* *}$ & $0.669^{* *}$ & 1 & & & & & & \\
\hline \multicolumn{12}{|l|}{ Burnout } \\
\hline 6. Personal accomplishment & $0.364^{* *}$ & $0.207^{* *}$ & $0.092^{* *}$ & $0.200^{* *}$ & $0.109^{* *}$ & 1 & & & & & \\
\hline 7. Depersonalization & $-0.286^{* *}$ & $-0.162^{* *}$ & $-0.219^{* *}$ & $-0.282^{* *}$ & $-0.194^{* *}$ & $-0.235^{* *}$ & 1 & & & & \\
\hline 8. Emotional exhaustion & $-0.171^{* *}$ & $-0.054^{* *}$ & $-0.340^{* *}$ & $-0.376^{* *}$ & $-0.283^{* *}$ & $-0.071^{* *}$ & $0.536^{* *}$ & 1 & & & \\
\hline \multicolumn{12}{|l|}{ Turnover intention } \\
\hline 9. TIS-I & $-0.179^{* *}$ & $-0.131^{* *}$ & $-0.448^{* *}$ & $-0.411^{* *}$ & $-0.407^{* *}$ & $-0.132^{* *}$ & $0.313^{* *}$ & $0.409^{* *}$ & 1 & & \\
\hline 10. TIS-II & $-0.061^{* *}$ & -0.005 & $-0.228^{* *}$ & $-0.175^{* *}$ & $-0.217^{* *}$ & $-0.152^{* *}$ & $0.051^{* *}$ & $0.141^{* *}$ & $0.466^{* *}$ & 1 & \\
\hline 11. TIS-III & $-0.172^{* *}$ & $-0.124^{* *}$ & $-0.363^{* *}$ & $-0.344^{* *}$ & $-0.326^{* *}$ & $-0.114^{* *}$ & $0.308^{* *}$ & $0.374^{* *}$ & $0.764^{* *}$ & $0.429^{* *}$ & 1 \\
\hline
\end{tabular}

Note: ${ }^{* *}: p<0.001$

TIS-I Turnover intention scale-I; TIS-II Turnover intention scale- II; TIS-III Turnover intention scale- III

0.42) had significant direct effects on turnover intention, but the direct effect of professional identity $(P>0.05)$ was not significant. As for indirect effects, it was found that the effect of professional identity $(\beta=-0.27,95 \% \mathrm{CI}$ : -0.32 to -0.23 ) on turnover intention was mediated by both job satisfaction and burnout. Simultaneously, burnout was also acted as a mediator for the relationship between job satisfaction and turnover intention $(\beta=-0.15$, 95\% CI: -0.19 to -0.12 ). In addition, we also found the mediation effect of job satisfaction on the relationship between professional identity and burnout $(\beta=-0.15$, 95\%CI: -0.18 to -0.12 ).

\section{Discussion}

The demand for primary healthcare services among the Chinese population is increasing and GPs constitute an essential part of the human resources need to provide these services. Training and retention of GPs are

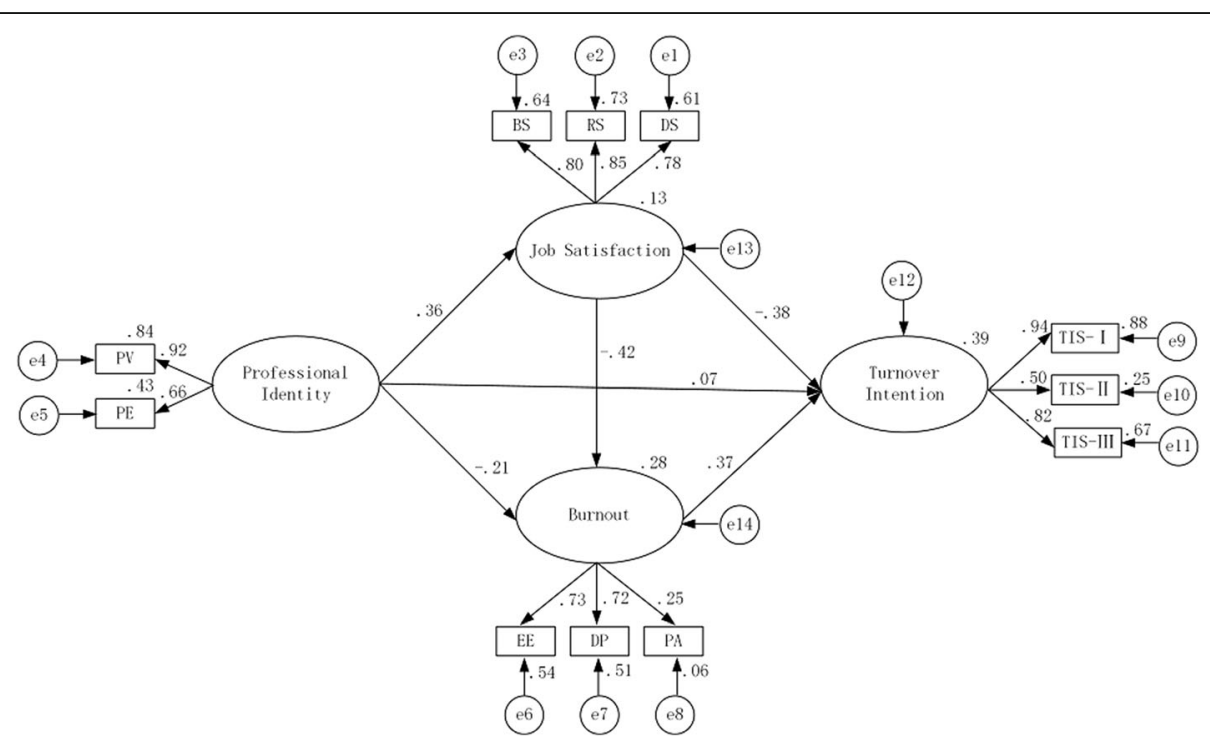

Fig. 2 Model paths and standardized coefficients on synthesized relationship among professional identity, job satisfaction, burnout and turnover intention (PV: professional value, PE: professional efficacy, BS: basic satisfaction, RS: relationship satisfaction, DS: development satisfaction) 
Table 3 Total, direct, indirect effects of model paths

\begin{tabular}{lllllll}
\hline Model paths & Total effect & $\mathbf{9 5 \%} \mathbf{C l}$ & Direct effects & $\mathbf{9 5 \%} \mathbf{C l}$ & Indirect effects & $\mathbf{9 5 \% C l}$ \\
\hline Professional identity $\rightarrow$ Job satisfaction & $0.36^{* *}$ & $(0.29,0.42)$ & $0.36^{* *}$ & $(0.29,0.42)$ & - & - \\
Professional identity $\rightarrow$ Burnout & $-0.36^{* *}$ & $(-0.42,-0.29)$ & $-0.21^{* *}$ & $(-0.28,-0.12)$ & $-0.15^{* *}$ & $(-0.18,-0.12)$ \\
Professional identity $\rightarrow$ Turnover intention & $-0.20^{*}$ & $(-0.26,-0.17)$ & 0.07 & $(-0.02,0.11)$ & $-0.27^{* *}$ & $(-0.32,-0.23)$ \\
Job satisfaction $\rightarrow$ Burnout & $-0.42^{* *}$ & $(-0.47,-0.36)$ & $-0.42^{* *}$ & $(-0.47,-0.36)$ & - & - \\
Job satisfaction $\rightarrow$ Turnover intention & $-0.54^{* *}$ & $(-0.57,-0.49)$ & $-0.38^{* *}$ & $(-0.43,-0.32)$ & $-0.15^{* *}$ & $(-0.19,-0.12)$ \\
Burnout $\rightarrow$ Turnover intention & $0.37^{* *}$ & $(0.32,0.42)$ & $0.37^{* *}$ & $(0.32,0.42)$ & - & - \\
\hline
\end{tabular}

${ }^{*} p<0.05 ;{ }^{* *} p<0.001$

prudent strategies to improve quality care outcomes. Improvement in professional identity and job satisfaction, and decreasing in burnout and turnover intention among GPs are important for the provision of highquality patient care. Identifying the interrelationships between professional identity, job satisfaction, burnout, and turnover intention among Chinese GPs would help the Chinese government to implement effective plans to strengthen the GPs workforce and improve the occupational attractiveness of GPs.

\section{Summary of main findings}

This study has explored the status of turnover intention and the associations between professional identity, burnout and job satisfaction and turnover intention among urban GPs in China.

Overall, the study showed that $71.1 \%$ of Chinese urban GPs reported moderate or higher levels of intention to quit their jobs, which is higher than that of village doctors (36.8\%) [38] and health inspectors in China (45.3\%) [22]. The turnover intention rate in this study is also higher than the reporting rates found in developed countries (e.g., New Zealand, Sweden, and Finland) [3941]. The differences might be at least partly attributable to the participants' characteristics (i.e., age, education, income level, practice setting (rural/urban areas), sample size, and the measurement of turnover intention). In addition, the study indicated that $37.5 \%$ Chinese urban GPs were dissatisfied with their current job, which is higher than a study performed in Denmark (22.1\%) [42]. More than half of GPs (51.6\%) reported higher levels of job satisfaction. The rate of high job satisfaction in the current study is in the middle of reporting rates found in developed countries (e.g., Germany (42\%) [43] and Canada (72\%)) [44].

\section{Job satisfaction had direct and indirect effects on turnover intention}

Job satisfaction was an important factor that had both direct and indirect effects on turnover intention. Job satisfaction was associated with an individual's perceptions and evaluation of the job, and this perception is influenced by person-specific status such as demands, values and expectations. Therefore, GPs with higher levels of job satisfaction tended to have higher enthusiasm for work and achieve a greater accomplishment from works they do, which in turn reduced the incidence of burnout. Moreover, previous literature found that burnout increased the risk of intention to leave [45]; thus, in this study the effect of job satisfaction on turnover intention can be mediated by burnout, which supported our hypotheses.

\section{Burnout had a directly positive effect on turnover intention}

In our study, we found that burnout had a directly positive effect on turnover intention. Similar to previous studies [46, 47], this study showed that burnout positively linked with turnover intention. According to the 2014 Chinese Medical Doctors Association report, $66 \%$ of GPs worked more than $40 \mathrm{~h}$ per week [48]. In China, the income of GPs was less than average income and far less than specialists' income, especially among those working in primary heath institutions. Chinese GPs were paid within a reference range set by the government though the range may vary depending on the area and their work tenure [11]. Due to the heavy workload, and low level of income, GPs often report poor experience on work, and they sometimes have faced distrust from patients in the Chinese primary care sector, which further resulted in their burnout [4951]. Based on the previously published literatures $[52,53]$, individuals who was in a status of burnout in a long time was unable to cope with the work pressure, and eventually led to resignation. This finding suggests that a reduction in burnout could serve as an effective way to reduce turnover intention, and provides new insights for future studies on ways to reduce the occupational burnout and indirectly address high turnover intention problems among GPs. Actions such as reducing the work intensity, increasing the wages of GPs, providing career development opportunities for GPs, and improving the skill and health service delivery ability of GPs are warranted to reduce the level of burnout of GPs. 
The mediating effects of job satisfaction and burnout on GPs' turnover intention

Our results were in agreement with previous studies [22, $54,55]$ showing that professional identity had a positive effect on job satisfaction and a negative effect on burnout. When individuals had a high degree of identity with their career, they would devote more time and efforts and vigour to their practice field, and the job dissatisfaction resulted from work environment and condition may be reduced or even eliminated [56]. Moreover, individuals had a high professional self-concept (a perception of oneself as a member of the profession), which could reduce the incidence of burnout [57]. Combining the significant associations of turnover intention with job satisfaction and burnout, it is not difficult to understand indirect effect of professional identity on turnover intention.

Intriguingly, we found that professional identity had no direct effect on turnover intention, which was inconsistent with previous studies $[54,58]$. One possible interpretation could be that in this study, professional identity focused on the GPs' perception on value of healthcare work itself, instead of their current position. In current context of Chinese primary care institutions, GPs often undertook a large amount of basic medical and public health service delivery, but usually earned fewer wage compared with doctors in hospitals. Therefore, those GPs with a high level of professional identity may also plan to leave their current job and enter advanced health institutions.

\section{Strengths and limitations}

This study has several strengths. First, to date, this is the first study to assess the mediating effects of job satisfaction and burnout on turnover intention among Chinese urban GPs based on a national representative sample. Second, we examined the interrelationships between professional identity, job satisfaction, burnout, and turnover intention. The results of our study not only can provide a new insight for GPs' intention to leave their present jobs, but also serve as new methods to address the high turnover issues among GPs in China. Future studies on constructing different models to examine the mechanism of professional identity on turnover intention by introducing other mediator factors are needed.

This study had several limitations. First, the analysis of cross-sectional data limited our ability to establish causal relationships among study variables. In addition, variables in our study were collected based on self-reported measurement, which was a potential source of measurement error. However, previous studies have suggested that there was qualified agreement between online self- reported and objected measured data, which were sufficiently valid for epidemiological investigations [59].

\section{Implications for research and practice}

GPs play important roles in enhancing quality of primary health care in the health care system. Awareness and management of turnover intention among GPs may stabilize the workforce in the primary health care system. Thus, policy makers of the country's health care service should take actions to improve job satisfaction and reduce the burnout of GPs. In addition, measures should be taken to improve GPs' professional identity that could help to increase job satisfaction and reduce occupational burnout.

\section{Conclusions}

In conclusion, three affecting paths of turnover intention were identified in our study. Job satisfaction, professional identity and burnout were all strong predicators of turnover intention. Professional identity had an indirect effect on turnover intention through job satisfaction and burnout instead of affecting turnover intention directly. Job satisfaction and burnout had significantly direct effects on turnover intention.

\section{Abbreviations \\ CHC: Community health center; $\mathrm{CHI}$ : Community health institution; \\ CFI: Comparative fit index; CHS: Community health service; GFI: Goodness-of- fit index; GP: General practitioner; IFI: Incremental fit index; MBI-HSS: Maslach burnout inventory-human services survey; NFI: Normed fit index; \\ RMSEA: Root mean square error of approximation; SEM: Structural equation modeling; THC: Township health center; TLI: Tucker-Lewis index}

\section{Supplementary Information}

The online version contains supplementary material available at https://doi. org/10.1186/s12913-021-06322-6.

\section{Additional file 1. Questionnaire.}

\section{Acknowledgments}

We would like to thank the GPs who participated in this research and staff members of Community Health Association of China involved in this study for their efforts in the data collection.

\section{Authors' contributions}

$\mathrm{TZ}$, JF, and $\mathrm{YG}$ conceived and designed the study. TZ, JF, and BP participated in the acquisition of data. TZ analyzed the data. HJ and BP gave advice on methodology. TZ and JF drafted the manuscript, and $\mathrm{HJ}, \mathrm{XS}, \mathrm{BP}$, and YG revised the manuscript. All authors read and approved the final manuscript. YG is the guarantors of this work and had full access to all the data in the study and takes responsibility for its integrity and the accuracy of the data analysis.

\section{Funding}

This study was supported by the Young Scientists Fund of the National Natural Science Foundation of China (Grant No. 71804049) and the Fundamental Research Funds for the Central Universities, Huazhong University of Science and Technology (2020kfyXJJS059). The funder had no role in study design, data collection and analysis, decision to publish, or preparation of the manuscript. 


\section{Availability of data and materials}

Data may be made available by contacting the corresponding author.

\section{Declarations}

\section{Ethics approval and consent to participate}

The study was approved by the Ethics Committee of the Tongji Medical College Institutional Review Board, Huazhong University of Science and Technology, Wuhan, China. Informed consent was obtained from all survey participants. All methods were performed in accordance with the relevant guidelines and regulations.

\section{Consent for publication}

Not applicable.

\section{Competing interests}

We declare that we have no conflict of interests.

\section{Author details}

${ }^{1}$ Department of Health Management, School of Medicine and Health Management, Tongji Medical College, Huazhong University of Science and Technology, Wuhan, Hubei, China. ${ }^{2}$ Department of Social Medicine and Health Service Management, School of Public Health, Hangzhou Normal University, Hangzhou, Zhejiang, China. ${ }^{3}$ Department of Social Medicine and Health Management, School of Public Health, Tongji Medical College, Huazhong University of Science and Technology, No. 13 Hangkong Road, Wuhan 430030, Hubei, China. ${ }^{4}$ Centre for Alcohol Policy Research, School of Psychology and Public Health, La Trobe University, Melbourne, Victoria, Australia. ${ }^{5}$ Centre for Health Equity, Melbourne School of Population and Global Health, University of Melbourne, Melbourne, Victoria, Australia. ${ }^{6}$ School of Business and Tourism, Sichuan Agricultural University, Chengdu, Sichuan, China.

Received: 10 December 2020 Accepted: 25 March 2021

Published online: 26 April 2021

\section{References}

1. Yu S, Zhenni L, Pengqian F. Factors influencing the turnover intention of chinese community health service workers based on the investigation results of five provinces. J Community Health. 2013;38:1058-66.

2. Murthy NRV, Okunade AA. Managed care, deficit financing, and aggregate health care expenditure in the United States: a cointegration analysis. Health Care Manag Sci. 2000;3(4):279-85. https://doi.org/10.1023/A:101 9066012984.

3. Li H, Liu K, Gu J, Zhang Y, Qiao Y, Sun X. The development and impact of primary health care in China from 1949 to 2015: a focused review. Int J Health Plann Manag. 2017;32(3):339-50. https://doi.org/10.1002/hpm.2435.

4. Winnie $Y$, William H. Harnessing the privatisation of China's fragmented health-care delivery. Lancet. 2014;384:805-18.

5. Opinions on reforming and improving the training and use of incentives for general practitioners. Available from http://www.gov.cn/zhengce/content/2 018-01/24/content_5260073.htm. Accessed 1 Apr 2021.

6. The guidance of the State Council on the establishment of the genenral practitioner system. Available from http://www.gov.cn/zwgk/2011-07/07/ content_1901099.htm. Accessed 1 Apr 2021.

7. Shuang W, Fu X, Liu Z, Bing W, Tang Y, Feng H, et al. General practitioner education reform in China: most undergraduate medical students do not choose general practitioner as a career under the $5+3$ model. Health Prof Educ. 2017:4:127-32.

8. Qiu C. More doctors around you. In: People's daily. Beijing: People's Daily Press; 2019

9. Shu Z, Wang Z, Chen R, Li M, Lou J, Huang X, et al. Allocation and development of the general practitioner workforce in China from 2012 to 2015: a literature review. Lancet. 2017;390:S91. https://doi.org/10.1016/S014 0-6736(17)33229-4.

10. Yip WC, Hsiao WC, Chen W, Hu S, Ma J, Maynard A. Early appraisal of China's huge and complex health-care reforms. Lancet. 2012;379(9818):83342. https://doi.org/10.1016/S0140-6736(11)61880-1.

11. Gan Y, Gong Y, Chen Y, Cao S, Li L, Zhou Y, et al. Turnover intention and related factors among general practitioners in Hubei, China: a crosssectional study. BMC Fam Pract. 2018;19:1-9.
12. Zhang M, Wang W, Millar R, Li G, Yan F. Coping and compromise: a qualitative study of how primary health care providers respond to health reform in China. Hum Resour Health. 2017;15:1-12.

13. Chang GM, Wang S, De-Xin M, Wei HJ, Luo QD, Chao F, et al. Turnover intention of general practitioners and its influencing factors. Chinese General Pract. 2016;19:3008-12

14. Allen $T$, Whittaker $W$, Sutton $M$. Does the proportion of pay linked to performance affect the job satisfaction of general practitioners? Soc Sci Med. 2017;173:9-17. https://doi.org/10.1016/j.socscimed.2016.11.028.

15. Pit SW, Hansen $\mathrm{V}$. The relationship between lifestyle, occupational health, and work-related factors with presenteeism amongst general practitioners. Arch Environ Occup H. 2016;71:49-56.

16. Bayati M, Rashidian A, Sarikhani Y, Lohivash S. Income inequality among general practitioners in Iran: a decomposition approach. BMC Health Serv Res. 2019;19(1):620. https://doi.org/10.1186/s12913-019-44 73-7.

17. Kuusio H, Heponiemi T, Vanska J, Aalto AM, Ruskoaho J, Elovainio M. Psychosocial stress factors and intention to leave job: differences between foreign-born and Finnish-born general practitioners. Scand J Public Healt 2013;41(4):405-11. https://doi.org/10.1177/1403494813477248.

18. Vanasse A, Scott S, Courteau J, Orzanco MG. Canadian family physicians' intentions to migrate: associated factors. Can Fam Physician. 2009;55:39697. e6.

19. Mobley $\mathrm{WH}$. Intermediate linkages in the relationship between job satisfaction and employee turnover. J Appl Psychol. 1977;62(2):237-40. https://doi.org/10.1037/0021-9010.62.2.237.

20. Siefert $K$, Jayaratne $S$, Chess WA. Job satisfaction, burnout, and turnover in health care social workers. Health Soc Work. 1991;16(3):193-202. https://doi. org/10.1093/hsw/16.3.193.

21. Sobrequés J, Cebrià J, Segura J, Rodríguez C, García M, Juncosa S. Job satisfaction and burnout in general practitioners. Aten Primaria. 2003;31(4): 227-33. https://doi.org/10.1016/S0212-6567(03)79164-1.

22. Zhang $W$, Meng H, Yang S, Liu D. The influence of professional identity, job satisfaction, and work engagement on turnover intention among township health inspectors in China. Int J Environ Res Public Health. 2018;15(5):988. https://doi.org/10.3390/ijerph15050988.

23. Selma S, Dogan S. Effects of the professional identity development programme on the professional identity, job satisfaction and burnout levels of nurses: a pilot study. Int J Nurs Pract. 2015;21:847-57.

24. Li L, Gan Y, Yang Y, Jiang H, Lu K, Zhou X, et al. Analysis on professional identity and related factors among Chinese general practitioners: a national cross-sectional study. BMC Fam Pract. 2020;21(1):1-8.

25. Fan X, Thompson B, Wang L. Effects of sample size, estimation methods, and model specification on structural equation modeling fit indexes. Struct Eq Model A Multidisciplinary J. 1999;6(1):56-83. https://doi.org/10.1080/1 0705519909540119.

26. Maccallum RC, Browne MW, Sugawara HM. Power analysis and determination of sample size for covariance structure modeling. Psychol Methods. 1996;1(2):130-49. https://doi.org/10.1037/1082989X.1.2.130

27. Preacher KJ, Coffman DL. Computing power and minimum sample size for RMSEA [computer software]. 2006. Available from http://quantpsy.org

28. Micheals CE, Spector PE. Causes of employee turnover: a test of the Mobley, Griffeth, hand, and Meglino model. J Appl Psychol. 1982;67(1):53-9. https:// doi.org/10.1037/0021-9010.67.1.53.

29. Lee D, Lee JY. A study on the relationships among role conflict, organizational commitment and intention to quit martrix organizational structure:using emploees from industrial technology research institute as example. Taipei: Institute of imformation Management, National Chiao Tung University; 2000.

30. Maslach C, Jackson SE. The measurement of experienced burnout. J Organ Behav. 1981;2(2):99-113. https://doi.org/10.1002/job.4030020205.

31. Shi L, Song K, Rane S, Sun X, Meng HLQ. Factors associated with job satisfaction by Chinese primary care providers. Prim Health Care Res Dev. 2014;15(01):46-57. https://doi.org/10.1017/S1463423612000692.

32. Wu H. Public hospital medical workers' prefessional identity research. Chengdu: Southwestern University of Finance and Economics; 2012.

33. Zhao H, Lu T, Zhang C, Deng F, Zheng J. Testing for reliability and validity of Chinese version of the nurse's career identity scale. Chinese Nurs Manag. 2010;10(11):49-51. 
34. West SG, Thoemmes F, Wu W. Introduction to structural equation modelling: using SPSS and AMOS. Br J Psychol. 2009;34:211-3.

35. Qiu L, Yang Q, Tong Y, Lu Z, Gong Y, Yin X. The mediating effects of stigma on depressive symptoms in patients with tuberculosis: a structural equation modeling approach. Front Psychiatry. 2018;9:1-9.

36. Zhang J, Li X, Fang $X$, Xiong Q. Discrimination experience and quality of life among rural-to-urban migrants in China: the mediation effect of expectation-reality discrepancy. Qual Life Res. 2009;18(3):291-300. https:// doi.org/10.1007/s11136-009-9454-6.

37. Quintana SM, Maxwell SE. Implications of recent developments in structural equation modeling for counseling psychology. Couns Psychol. 1999;27(4): 485-527. https://doi.org/10.1177/0011000099274002.

38. Fang $P$, Liu X, Huang $L$, Zhang $X$, Fang Z. Factors that influence the turnover intention of Chinese village doctors based on the investigation results of Xiangyang City in Hubei Province. Int J Equity Health. 2014;13:1-9.

39. McComb ED. Which psycho-demographic factors predict a doctor's intention to leave New Zealand general practice? N Z Med J. 2008;121(1273):25-36.

40. Eneroth M, Gustafsson Sendén M, Schenck Gustafsson K, Wall M, Fridner A. Threats or violence from patients was associated with turnover intention among foreign-born GPs - a comparison of four workplace factors associated with attitudes of wanting to quit one's job as a GP. Scand J Prim Health Care. 2017;35(2):208-13. https://doi.org/10.1080/02813432.201 7.1333319 .

41. Hannamaria K, Tarja H, Jukka VN, Anna-Mari A, Juho R, Marko E. Psychosocial stress factors and intention to leave job: differences between foreign-born and Finnish-born general practitioners. Scand J Public Health. 2013;41:405-11.

42. Noroxe KB, Pedersen AF, Bro F, Vedsted P. Mental well-being and job satisfaction among general practitioners: a nationwide cross-sectional survey in Denmark. BMC Fam Pract. 2018;19(1):130. https://doi.org/10.1186/ s12875-018-0809-3.

43. Leutgeb R, Frankenhauser-Mannuss J, Scheuer M, Szecsenyi J, Goetz K. Job satisfaction and stressors for working in out-of-hours care - a pilot study with general practitioners in a rural area of Germany. BMC Fam Pract. 2018; 19(1):95. https://doi.org/10.1186/s12875-018-0777-7.

44. Malhotra J, Wong E, Thind A. Canadian family physician job satisfaction is it changing in an evolving practice environment? An analysis of the 2013 National Physician Survey database. BMC Fam Pract. 2018;19(1):100. https:// doi.org/10.1186/s12875-018-0786-6.

45. Scanlan JN, Still M. Relationships between burnout, turnover intention, job satisfaction, job demands and job resources for mental health personnel in an Australian mental health service. BMC Health Serv Res. 2019;19:1-11.

46. Shimizu T, Feng $Q$, Nagata $S$. Relationship between turnover and burnout among Japanese hospital nurses. J Occup Health. 2005;47(4):334-6. https:// doi.org/10.1539/joh.47.334.

47. Liu W, Zhao S, Shi L, Zhang Z, Liu X, Li L, et al. Workplace violence, job satisfaction, burnout, perceived organisational support and their effects on turnover intention among Chinese nurses in tertiary hospitals: a crosssectional study. BMJ Open. 2018:8:1-11.

48. Chinese Medical Doctor Association. The fifth research reports of Chinese physician practice status 2014. http://www.cmda.net/zlwagzdt/596.jhtml.

49. Gan Y, Jiang H, Li L, Yang Y, Wang C, Liu J, et al. Prevalence of burnout and associated factors among general practitioners in Hubei, China: a crosssectional study. BMC Public Health. 2019;19:1607.

50. Kumar S. Burnout and Doctors: Prevalence, Prevention and intervention. Healthcare (Basel). 2016;4:37.

51. Lo D, Wu F, Chan M, Chu R, Li D. A systematic review of burnout among doctors in China: a cultural perspective. Asia Pac Fam Med. 2018;17(1):3. https://doi.org/10.1186/s12930-018-0040-3.

52. Jiang H, Ma L, Gao C, Li T, Huang L, Huang W. Satisfaction, burnout and intention to stay of emergency nurses in Shanghai. Emerg Med J. 2017; 34(7):448-53. https://doi.org/10.1136/emermed-2016-205886.

53. Na SY, Park H. The effect of nurse's emotional labor on turnover intention: mediation effect of burnout and moderated mediation effect of authentic leadership. J Korean Acad Nur. 2019;49(3):286-97. https://doi.org/10.4040/jka n.2019.49.3.286.

54. Selma S, Selma D. Relationship between job satisfaction, professional identity and intention to leave the profession among nurses in Turkey. J Nurs Manag. 2015;23:1076-85.
55. Mainous AG III, Rahmanian KP, Ledford CJW, Carek PJ. Professional identity, job satisfaction and commitment of nonphysician faculty in academic family medicine. Fam Med. 2018;50(10):739-45. https://doi.org/10.22454/Fa mMed.2018.273724.

56. Coetzee M, van Dyk J. Workplace bullying and turnover intention: exploring work engagement as a potential mediator. Psychol Rep. 2018;121(2):375-92. https://doi.org/10.1177/0033294117725073.

57. Yu J, Lee S, Kim M, Lim K, Chang K, Chae S. Professional self-concept and burnout among medical school faculty in South Korea: a crosssectional study. BMC Med Educ. 2019;19(1):248. https://doi.org/10.1186/ s12909-019-1682-z.

58. Jourdain $\mathrm{G}$, Chenevert D. Job demands-resources, burnout and intention to leave the nursing profession: a questionnaire survey. Int J Nurs Stud. 2010; 47(6):709-22. https://doi.org/10.1016/j.jinurstu.2009.11.007.

59. Ortiz-Panozo E, Yunes-Diaz E, Lajous M, Romieu I, Monge A, LopezRidaura R. Validity of self-reported anthropometry in adult Mexican women. Salud Publica Mex. 2017;59(3, may-jun):266-75. https://doi.org/1 $0.21149 / 7860$

\section{Publisher's Note}

Springer Nature remains neutral with regard to jurisdictional claims in published maps and institutional affiliations.

\section{Ready to submit your research? Choose BMC and benefit from:}

- fast, convenient online submission

- thorough peer review by experienced researchers in your field

- rapid publication on acceptance

- support for research data, including large and complex data types

- gold Open Access which fosters wider collaboration and increased citations

- maximum visibility for your research: over $100 \mathrm{M}$ website views per year

At BMC, research is always in progress.

Learn more biomedcentral.com/submissions 